\title{
Stimulus selection in discriminative taste-aversion learning in the rat
}

\author{
ALEXANDER F. LUONGO \\ University of California, Los Angeles, Los Angeles, California 90024
}

\begin{abstract}
In three experiments, rats were presented compound solutions consisting of a common element, saccharin, mixed with one of two different flavor elements, cinnamon and wintergreen. Rats in the experimental groups consistently received a toxicosis-inducing injection following one compound solution but not following the other compound solution. Rats in the control groups received toxicosis-inducing injections half the time following each of the compound solutions. After training in each experiment, there were tests for conditioning to the saccharin alone. The experimental groups drank significantly more than the control groups, indicating that the aversion to the partially reinforced saccharin in isolation was less when the different flavor cues were more highly correlated with reinforcement. In Experiment III, there was also a test for conditioning to the cinnamon or wintergreen flavor alone. The experimental group drank significantly less of the continuously reinforced flavor than the control group did of the partially reinforced flavor. These results are similar to those reported within more traditional conditioning paradigms.
\end{abstract}

When a rat consumes a flavored substance and later becomes ill, the animal will avoid consuming the flavored substance after recovery from illness. Using this basic operation, Garcia and his co-workers have reported two landmark findings: (a) the "belongingness" principle, i.e., the differential effectiveness of cues in relation to consequences (Garcia \& Koelling, 1966), and (b) learning with prolonged delay of reinforcement (Garcia, Ervin, \& Koelling, 1966). There is some controversy, however, about whether there are other phenomena that differentiate taste-aversion learning from traditional conditioning procedures.

For example, in the last 10 years there has been a resurgence of interest in the factors that affect conditionability of elements in compound conditioned stimuli. One fundamental and consistent finding is that a stimulus element shows little or no conditioning unless it is more highly correlated with reinforcement than are other stimulus elements in the compound. This result has appeared in two types of experiment: (a) the elements of a compound stimulus are arranged to be associated with different probabilities of reinforcement (Egger \& Miller, 1962; Wagner, Logan, Haberlandt, \& Price, 1968), and (b) an element is first conditioned

This report is based on a doctoral dissertation submitted to the University of California, Los Angeles in 1974. I am greatly indebted to Eric W. Holman for his guidance and encouragement as dissertation advisor. The research was supported by University of California Graduate Student Patent Fund Grant to the author and University of California, Los Angeles, Academic Senate Research Committee Grant 2386 to Eric W. Holman. Requests for reprints should be sent to Alexander F. Luongo, Department of Psychology, Loyola Marymount University, Los Angeles, California 90045. alone and then reinforced in compound with another element (Kamin, 1969). Rescorla and Wagner (1972) have advanced a model for Pavlovian conditioning with compound CSs that incorporates both types of results. These findings, however, have been based upon research using cues such as lights and tones and reinforcers such as food pellets and footshocks. There are still questions about analogous phenomena in taste-aversion learning.

Revusky (1971) has reported several experiments, using a procedure analagous to Kamin's, in which two differently flavored solutions are consumed sequentially prior to illness. When one flavored solution had been associated with illness prior to training, there was a small but significant reduction in conditioned aversion to the other flavor relative to appropriate controls. However, in a series of four similar experiments, Kalat and Rozin (1972) found no such effects. The discrepancy in findings suggests that this type of experimental design may not be very sensitive to interaction effects. Such effects might more readily be observed by using the design of Wagner et al. (1968).

Wagner et al. (1968) reported three experiments, involving both instrumental and classical conditioning, in which two stimulus compounds (A1L and A2L) were formed from a constant visual element (L) and either of two auditory components (All or A2). These two compounds were equally often presented, with half the total presentations followed by reinforcement. The visual element always had the same probability of reinforcement, its presence being associated with a $50 \%$ reinforcement schedule, its absence with no reinforcement. The control group received pseudodiscrimination training: the com- 
pounds containing A1 and A2 were each equally often associated with reinforcement and nonreinforcement. The experimental group received true discrimination training: the compound containing Al always signaled reinforcement, while the compound containing $\mathbf{A} 2$ always signaled nonreinforcement. Following training, all subjects were administered test trials on which $\mathrm{L}$ was presented alone. Simply on the basis of its probability of reinforcement, $\mathrm{L}$ alone should have been similarly responded to in the two groups. However, in all three experiments, the partially reinforced $\mathrm{L}$ element was a much less effective stimulus in isolation for the experimental than for the control group. Thus, the presence of a continuously reinforced cue reduced conditioning to the partially reinforced cue. The present experiments investigated whether or not a similar effect occurs in taste-aversion learning.

\section{EXPERIMENT I}

The first experiment is a direct analogue of the Wagner et al. (1968) study. Rats were presented compound solutions containing a common element (saccharin) and either of two different flavors (wintergreen and cinnamon). A true discrimination (TD) group received a toxicosis-inducing injection $100 \%$ of the time following one compound solution and a control injection $100 \%$ of the time following the other compound solution. A pseudodiscrimination (PD) group received $50 \%$ toxicoses-inducing and $50 \%$ control injections following each of the compounds. There were two additional control groups: a single-stimulus (SS) group, which received just the plain saccharin solution throughout the experiment and injections on a schedule identical to that of the PD group, and a no-discrimination (ND) group, which received the flavored compound solutions and control injections $100 \%$ of the time.

\footnotetext{
Method

Subjects. The subjects were 24 naive female SpragueDawley rats obtained at the age of about 90 days from Simonson Laboratories, Gilroy, California.

Materials. Plain $.16 \%$ sodium saccharin dissolved in water served as the training solution for the single-stimulus controls and as the test solution for all four groups in extinction. Flavor extracts were made of $2 \%$ oil of cinnamon or oil of wintergreen (methyl salicylate) dissolved in ethanol. The compound training solutions consisted of $.16 \%$ sodium saccharin and $1 \%$ cinnamon or wintergreen extract dissolved in water. The solutions were presented in 50-ml graduated test tubes with drinking spouts, and were attached to the home cages in place of the water bottles. The toxicosis-inducing agent was $.15 \mathrm{M} \mathrm{LiCl}$, and the control agent, .15M NaCl .

Procedure. The rats were housed in individual cages with constant temperature and illumination. Water was available ad lib, except for the period in which the solutions were presented. For 3 weeks prior to the experiment, the rats were habituated to handling and were maintained on a daily diet of $10 \mathrm{~g}$ of Purina Lab Chow. This feeding schedule was
}

maintaned throughout the experiment. T ammng and testung were conducted in home cages. The rats were removed from home cages for the administration of reinforcing or control injections only. The delay of injection from the lime of removal of the solutions ranged from 1 to $12 \mathrm{~min}$

There were 22 consecutive training days and 7 consecutive test days. A training day constituted a discrete trial and consisted of presenting $40 \mathrm{ml}$ of solution for $30 \mathrm{~min}$, followed by either reinforcing or control injection, intraperitoneally. The rats were assigned randomly to four treatment conditions: TD-One flavor in saccharin solution $\left(\mathrm{F}^{+} \mathrm{Sac}\right)$ was always followed by the reinforcing injection, and the second flavor in saccharin solution $\left(\mathrm{F}^{-} \mathrm{Sac}\right)$ was always followed by the control injection. For half the rats in this group, $\mathrm{F}^{+}$was cmnamon and $\mathrm{F}$ wintergreen; for the other half, $\mathrm{F}^{+}$was wintergreen and $\mathrm{F}$ was cinnamon. PD-Both solutions, designated $\mathrm{F} \pm$ Sac, were followed on half the trials by the reinforcing injection and on the other trials by the control injection. SS-Plain saccharin (Sac) was presented on each trial and reinforced according to the same schedule as Group PD. ND-Both solutions were presented on the same schedule as Group TD, but always followed by the control injection.

Day 1 was a nonreinforced trial for all groups; Day 2 was a reinforced trial for Groups TD, PD, and SS, and of course nonreinforced for Group ND. In Groups TD, PD, and ND, half the rats received the cinnamon-flavored solution on Day 1 and the wintergreen-flavored solution on Day 2, while the other rats received the opposite sequence. This procedure was used in order to check for unconditioned preferences between the two differently flavored solutions prior to reinforcement, and to allow for famliarization with the solutions. On Days 3-22, all the rats in Groups TD, PD, and ND received the cinnamonflavored solution on odd-numbered days and the wintergreenflavored solution on even-numbered days. Thus, the TD group was on a single-alternation reinforcement schedule. The PD group was on a double-alternation reinforcement schedule, nonreinforced on Days 3, 6. 7, 10, etc., and reinforced on Days 4, 5, 8 , 9, etc. The SS group was likewise on the same doublealternation reinforcement schedule as the PD group. The ND group received the identical flavor sequence described for TD and PD, but were always nonreinforced. Through Days 1-14, subjects were injected with $1 \mathrm{ml}$ of either $\mathrm{LiCl}$ or $\mathrm{NaCl}$; on Days 15-18, the dosage was increased to $2 \mathrm{ml}$, and on Days 19-22, to $3 \mathrm{ml}$. Pilot experiments indicated that such an increasing sequence of doses was more likely to produce discrimination performance in the TD group rather than nondiscriminative aversion or consumption.

Testing began on the day following the end of training and continued for 7 consecutive days. All subjects were presented with $40 \mathrm{ml}$ of $.16 \%$ plain saccharın solution for $30 \mathrm{~min}$ with all injections omitted (extınction).

\section{Results}

Figure 1 gives the median solution intake for all groups during training and extinction. Except for Group TD during training, each point represents a single day's intake; training days for $\mathrm{TD}\left(\mathrm{F}^{+} \mathrm{Sac}\right)$ and $\mathrm{TD}\left(\mathrm{F}^{-} \mathrm{Sac}\right)$ are grouped in pairs beginning with Days 3 and 4 , since each rat received each condition once in each pair of days. The medians for each group in total intake of solution summed for the 22 training days were: ND, 509; TD, 221; PD, 92; and SS, 82. The groups differed significantly (Kruskal-Wallis $H=13.07$, $\mathrm{df}=3, \mathrm{p}<.01)$. The TD group drank significantly less in training than the ND group $(T=22$, 
$p<.01) .^{\prime}$ However, the TD group did not drink significantly more than the PD and SS groups $(T=35, T=30)$; this was due to the fact that two subjects in the TD group suppressed drinking to both solutions midway in training, while one subject in the PD group failed to suppress drinking during training. For each of the other four TD subjects, $\mathrm{F}^{-}$Sac intake exceeded $\mathrm{F}^{+}$Sac intake for all pairs of days from Day 8 to the end of training, suggesting that the discrimination treatment was effective.

The medians for each group in total intake of plain saccharin solution for 7 extinction test days were: ND, 167.5; TD, 114; PD, 5; and SS, 5. The groups differed significantly (Kruskal-Wallis $H=14.86, \mathrm{df}=3, \mathrm{p}<.01)$. The TD group drank significantly less in extinction than the ND group $(T=24.5, p<.05)$, thus showing some aversion to plain saccharin solution. More importantly, however, the TD group drank significantly more than the PD and SS groups $(T=27, p<.06$; $\mathrm{T}=23.5, \mathrm{p}<.05)$, which did not differ from each other $(T=37)$. This effect was strong enough to occur despite the two TD subjects which had failed to discriminate and the PD subject which had failed to suppress drinking.

Consequently, the result of this study indicated that a partially reinforced cue $(\mathrm{Sac})$ exerted much less effective aversive control in isolation when it had been experienced in compounds $\left(\mathrm{F}^{+} \mathrm{Sac}\right.$ and $\mathrm{F}^{-} \mathrm{Sac}$ ) containing elements more highly correlated with reinforcement than when it had been experienced in similar compounds which did not contain more highly correlated elements. Moreover, the aversive control acquired by the Sac cue in the PD condition was equivalent to that in the SS condition which was partially reinforced on the Sac cue only.

\section{EXPERIMENT II}

This experiment was a modified replication of Experiment I. Only Groups TD and PD were used, and the training procedure involved two additional controls: limited amounts of solution were presented in order to equalize consumption, and the same schedule of reinforced and nonreinforced trials was used for both groups.

\section{Method}

Subjects. The subjects were 25 naive female Sprague-Dawley rats obtained at the age of about 90 days from Simonson Laboratories, Gilroy, California.

Materials. The materials were the same as in Experiment I.

Procedure. The rats were fed, watered, and handled as in Experiment $I$. There were 32 consecutive training days organized into four eight-trial blocks and 28 consecutive test days. A training day constituted a discrete trial and consisted of presenting $3 \mathrm{ml}$ of solution for $30 \mathrm{~min}$ followed either by an

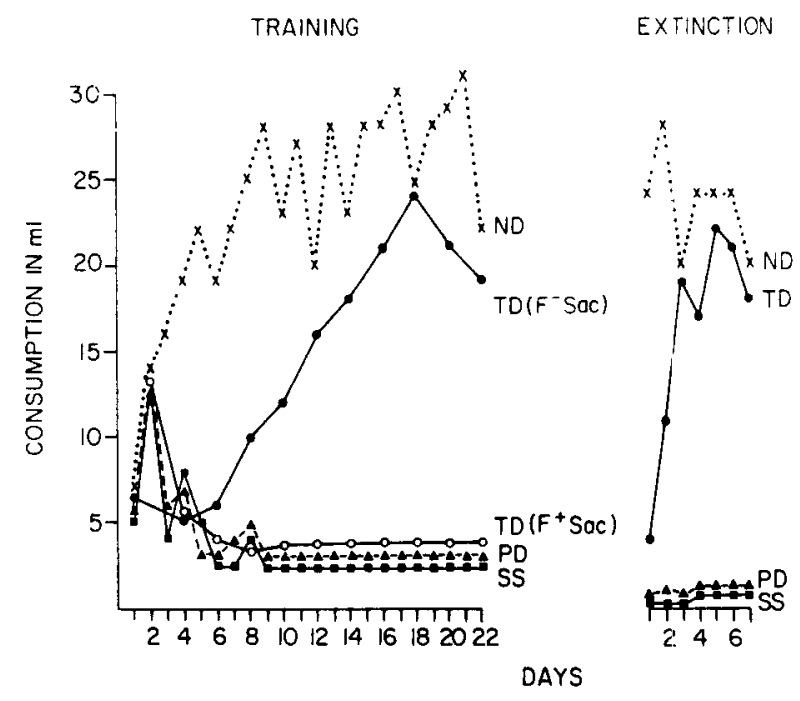

Figure 1. Median daily consumption of solution during training and extinction as a function of days for the four treatment conditions in Experiment $I$.

intraperitoneal reinforcing injection or by nothing, as appropriate. Of the 25 rats, 13 were randomly assigned to Group TD and the other 12 to Group PD. In each block of training trials, both groups were nonreinforced on Days 1, 2, 4, and 6, and reinforced on Days 3, 5, 7, and 8. Seven rats in the TD group received cinnamon-flavored saccharin on Days 1, 2, 4, and 6, and wintergreen-flavored saccharin on Days 3, 5, 7, and 8; six rats in the TD group received wintergreen-flavored saccharin on Days 1, 2, 4, and 6 and cinnamon-flavored saccharin on Days 3, 5, 7, and 8. The PD rats received the sequence cinnamon, wintergreen, cinnamon, wintergreen on both Nonreinforced Days 1, 2, 4, and 6 and Reinforced Days 3, 5, 7, and 8. On Days 1-18, the rats were injected (IP) on appropriate trials with $1 \mathrm{ml} \mathrm{LiCl}$; on Days 17-22, the dosage was increased to $2 \mathrm{ml}$, and on Days 23-32, to $4 \mathrm{ml}$. No control injections were given.

Testing commenced on the day following the end of training and continued for 28 consecutive days. All subjects were presented with $40 \mathrm{ml}$ of $.16 \%$ plain saccharin solution for $30 \mathrm{~min}$ with all injections omitted (extinction).

\section{Results}

The medians for the TD and PD groups in total intake of flavored saccharin solution for the 32 training days were: TD, 40.5; PD, 37. The groups did not differ significantly $(T=156)$. Upon inspection of the acquisition data for Group TD, it was determined that seven rats drank $2.5 \mathrm{ml}$ or more of the $\mathrm{F}^{-} \mathrm{Sac}$ solution and $1.0 \mathrm{ml}$ or less of the $\mathrm{F}^{+} \mathrm{Sac}$ solution at the end of training, and therefore evidenced learning of the discrimination (Subgroup TDL), while six rats drank $1 \mathrm{ml}$ or less of both solutions at the end of training (Subgroup TDNL). In Group PD, 11 rats drank $1 \mathrm{ml}$ or less of both solutions at the end of training, while 1 rat continued to drink $2.5 \mathrm{ml}$ or more of both solutions.

Figure 2 gives the day-by-day median solution intake in extinction for Subgroups TDL, TDNL, and Group PD. The medians for each group and 
EXTINCTION

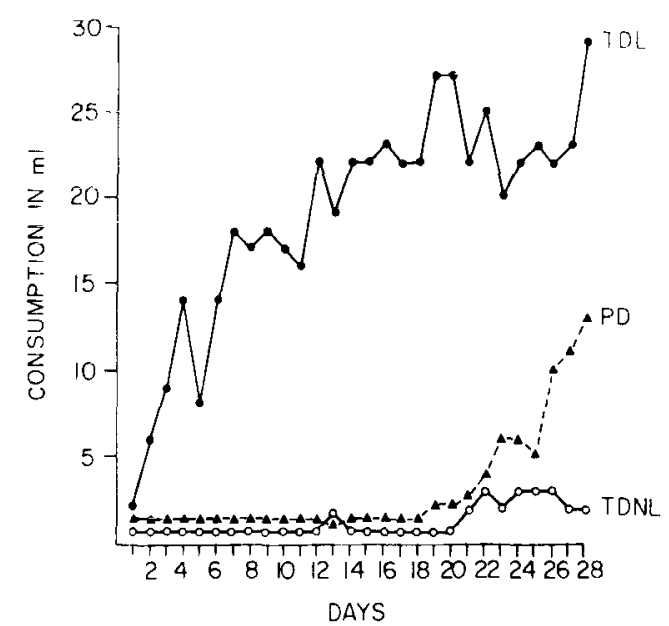

Figure 2. Median daily consumption of solution during extinction as a function of days for the TD and PD treatment conditions in Experiment II.

subgroup in total intake of plain saccharin solution for the 28 extinction test days were: TD, 362; TDL, 478.5; TDNL, 37.5; PD, 111.5. The overall TD and PD groups did not differ significantly in total intake $\left(T^{\prime}=127.5\right)$. However, when the data for the overall $T D$ and $P D$ groups were examined in 14-day blocks, the TD group drank significantly more than the PD group in Block 1-14 $\left(\mathrm{T}^{\prime}=119.5, \mathrm{p}=.05\right)$, but not in Block 15-28 $\left(T^{\prime}=126\right)$; not surprisingly, the effects of training dissipated toward the end of extinction. Also, the TDL and TDNL subgroups were examined separately for the entire 28 extinction test days. The TDL subgroup differed significantly from both the PD group $(T=28, p<.01)$, and the TDNL subgroup $\left(\mathrm{T}^{\prime}=21, \mathrm{p}<.01\right)$. However, the TDNL subgroup did not differ significantly from the PD group $\left(\mathrm{T}^{\prime}=43.5\right)$.

Therefore, the result of this study, with appropriate control for intake and identical reinforcement schedule in training, corroborated the finding from Experiment I. The partially reinforced common cue element Sac acquired significantly less aversive control in the TD condition than in the PD condition. The result with respect to the TDL and TDNL subgroups further indicated that learning the discrimination in training, and not mere exposure to a discrimination regimen, is crucial in obtaining the effect.

\section{EXPERIMENT III}

In Experiments I and II, it was shown that true discrimination (TD) training on two differently flavored saccharin solutions $\left(\mathrm{F}^{+} \mathrm{Sac}\right.$ and $\left.\mathrm{F}^{-} \mathrm{Sac}\right)$ reduced the amount of aversion conditioned to the common cue element (Sac) relative to pseudodiscrimination (PD) training. The present experiment addressed the complementary question, namely, to what extent was aversiveness conditioned to the $\mathrm{F}^{+}$ cue alone in the TD condition relative to the $\mathrm{F}^{ \pm}$cue in the $\mathrm{PD}$ condition.

Rescorla and Wagner's (1972) model for Pavlovian conditioning has the following properties: (1) the asymptotic totall $\mathrm{CR}$ which a US may support is dependent upon intensity and frequency of the US, and (2) the effect of a reinforcement or nonreinforcement in changing the associative strength of a stimulus depends upon the existing associative strength, not only of that stimulus, but also of other stimuli concurrently present. In the present experiment, as in Experiments I and II, training conditions were arranged such that both TD and PD groups were equated on intensity and overall frequency of reinforcement. The $\mathrm{F}^{+}$Sac compound was $100 \%$ reinforced for Group TD, while either $\mathrm{F}^{ \pm}$compound was $50 \%$ reinforced for Group PD. Therefore, at asymptote, the total CR to the $\mathrm{F}^{+}$Sac compound in Group TD is assumed to be greater than the total $\mathrm{CR}$ to either $\mathrm{F} \pm$ Sac compound in Group PD. Since it is also known from Experiments I and II that the CR to the common element Sac is smaller for Group TD than for Group PD, the Rescorla and Wagner model predicts that the $\mathrm{F}^{+}$cue should demonstrate a larger $\mathrm{CR}$ than the $\mathrm{F}^{ \pm}$cue.

\section{Method}

Subjects. The subjects were 24 nave female Sprague-Dawley rats obtained at the age of about 90 days from Simonson Laboratories, Gilroy, Calıfornia.

Materials. The materials were the same as in Experıment I.

Procedure. Two weeks prior to the experiment, the rats were habituated to handling and to the following maintenance schedule: $23 \mathrm{~h}$ water ad lib with no food; $1 \mathrm{~h}$ food ad lib with no water. The training solutions, limited in amount to $3 \mathrm{ml}$, were presented for $30 \mathrm{~min}$ immediately following the $1 \mathrm{~h}$ access to dry food. This procedure was employed throughout the first 25 days of training in order to insure that all subjects intially consumed the training solutions. For the remainder of the experiment, the rats were fed $5 \mathrm{~g}$ of dry food with no water for $20 \mathrm{~min}$ and then presented the training solutions for $30 \mathrm{~min}$; after this, the water bottles were replaced and the rats were fed an additional $5 \mathrm{~g}$ of food. The reduction in thirst served to enhance suppression in the PD group during the remainder of training.

There were 32 consecutive trainıng days. The organization of training days into eight-trial blocks, the types and amount of training solutions presented, the assignment of subjects into TD and PD treatments, and the training solution presentationreinforcement sequence for both groups were identical to those described in Experiment II. On Days 1-10, the rats were injected (IP) on the appropriate trials with $1 \mathrm{ml}$ of $\mathrm{LiCl}$; on Days 11-14, the dosage was increased to $2 \mathrm{ml}$; on Days $15-18$, to $3 \mathrm{ml}$; on Days 19-22, to $4 \mathrm{ml}$; and on Days 23-32, to $5 \mathrm{ml}$. No control injections were given.

Testing began on the day following the end of training and was divided into two phases. In the 16 days of Phase 1, the rats in the TD group were presented with $40 \mathrm{ml}$ of the flavor extract associated with reinforcement $\left(\mathrm{F}^{+}\right)$in plain water for $30 \mathrm{~min}$; the rats in the PD group were presented with $40 \mathrm{ml}$ of partially reinforced flavor extract ( $\left.F^{ \pm}\right)$in water, cinnamon for half the rats and wintergreen for the other half. 
In the 8 days of Phase 2, all the rats were presented with $40 \mathrm{ml}$ of plan . $16 \%$ saccharin solution for $30 \mathrm{~m} m$.

\section{Results}

One rat in the TD group died during training; therefore, the data were analyzed for the remaining 23 subjects. The medians for the TD and PD groups in total intake of flavored saccharin solution for the 32 training days were: TD, 62.5; $\mathrm{PD}, 62$. The groups did not differ significantly $\left(\mathrm{T}^{\prime}=124\right)$. Upon inspection of the acquisition data for Group TD, it was determined that nine rats drank $2.5 \mathrm{ml}$ or more of the $\mathrm{F}^{-}$Sac solution and $1 \mathrm{ml}$ or less of the $\mathrm{F}^{+}$Sac solution at the end of training and therefore evidenced learning of the discrimination, while two rats drank $1 \mathrm{ml}$ or less of both solutions at the end of training. Conversely, three rats in the PD group drank $2.5 \mathrm{ml}$ or more of both solutions at the end of training; the remaining nine PD rats drank $1 \mathrm{ml}$ or less of both solutions at the end of training. Therefore, the thirst manipulation was successful in enhancing discrimination in the TD group at the cost of reducing suppression in the PD group.

Figure 3 gives the day-by-day median solution intake for Groups TD and PD during Phases 1 and 2 of extinction. In Phase 1 extinction, the median for the TD group in total intaks of $F^{+}$flavor in water for the 16 extinction test days was 28 , while the median for the PD group in total intake of $F^{ \pm}$ flavor in water was 55. The TD group drank significantly less than the PD group $\left(\mathrm{T}^{\prime}=99\right.$, $p<.05$ ). In Phase 2 extinction, the medians for each group in total intake of plain saccharin solution for the 8 extinction test days were: TD, 140; $P D, 89.5$. The TD group drank significantly more than the PD group ( $T=84, \mathrm{p}<.01$ ).

The finding from Phase 1 extinction, that the TD group showed significantly greater resistance to extinction to the $\mathrm{F}^{+}$cue than the $\mathrm{PD}$ group to the partially reinforced $\mathrm{F}^{ \pm}$cue, lends support to the prediction from the Rescorla and Wagner (1972) model. The finding from Phase 2 extinction, that the TD group demonstrated significantly less resistance to extinction to the common cue element (Sac) than the PD group, confirmed the results of Experiments I and II in the present series and the general finding of Wagner et al. (1968). This effect was robust as it was still present after interposition of the Phase 1 extinction trials.

\section{GENERAL DISCUSSION}

The effects of true discrimination and pseudodiscrimination training on compound solutions consisting of saccharin and different flavors were examined in three experiments. The results of

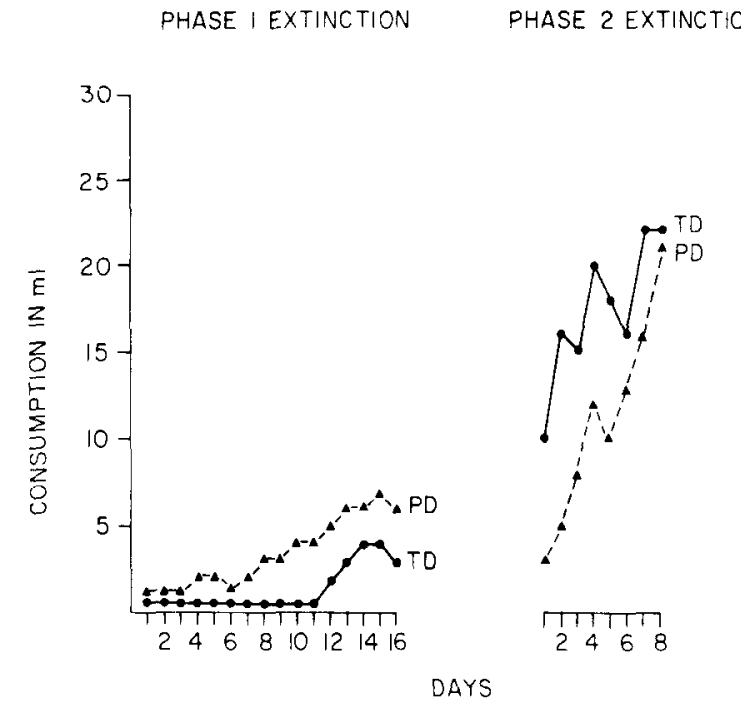

Figure 3. Median daily consumption of solution during extinction as a function of days for compound stimulus components and TD and PD treatment conditions in Experiment III.

these studies indicated that a partially reinforced cue was much less likely to be an effective stimulus in isolation when it had been experienced in compounds containing elements more highly correlated with reinforcement than when it had been experienced in similar compounds which did not contain more highly correlated elements. These rsults are directly parallel to those reported within more traditional conditioning paradigms (Wagner et al., 1968).

Furthermore, when the flavor element occupying the role of $\mathrm{F}^{+}$in the TD condition was compared to the flavor element occupying the role of $\mathrm{F}^{+}$ in the PD condition, the continuously reinforced flavor $\left(\mathrm{F}^{+}\right)$showed greater resistance to extinction than the partially reinforced flavor $\left(\mathrm{F}^{ \pm}\right)$. This result is a straightforward derivation from the Rescorla and Wagner (1972) model of stimulus selection in Pavlovian conditioning with compound CSs containing a common element, and is similar to the findings of Wagner et al. (1968, Experiments 2 and 3). However, in other experiments of similar design (Freides, 1957; Jenkins, 1961; Wagner et al., 1968, Experiment 1), subjects exposed to a partially reinforced cue showed equivalent or greater resistance to extinction than subjects exposed to the continuously reinforced cue from prior discrimination training. The discrepancy in findings appears to be readily reconciled in terms of the nature of the reinforcer employed. The three latter studies involved positive reinforcers. When aversive reinforcers were utilized, as in Experiment III in the present series and in Wagner et al. (1968, Experiments 2 and 3), the analysis of Rescorla and 
Wagner (1972) was supported within both telereceptıve cutaneous and gustatory-visceral conditioning paradigms.

\section{REFERENCES}

Egger, D. M., \& Miller, N. E. Secondary reintorcement in rats as a function of information value and reliability of the stimulus Journal of Expenmental Psychology, 1962, 64, 97.

Fpeides, D. Goal-box cues and pattern of ienforcement. Iournal of Expermental Psychology, 1957, 53, 361

Garcia, J., \& Koelina, R. A. Relation of cue to consequence in avoldance learning. Psychonomic Sctence, 1906, 4, 123-124.

Garcia, J., Ervin, F. R., \& Koelling, R. A. Learning with prolonged delay of reintorcement. Psychonomic Science, $1906,5,121-122$.

Jenkins, H. M. The effect of discrimination training on extinction. Journal of Experimental Psychology, 1961, 61, 111.

Kalat, J W., \& Rozin, P. You can lead a rat to poison, but you can't make hım think. In M. E. P. Seligman \& J. Hager (Eds.), Biological boundanies of learning. New York: Academic Press, 1972.
Kamin, L J Predictabilly, surprise, attention, and conditioning In B A (ampbell \& R M Chuili (Lds.). Punshment and wersu's behavor. New York. Appieron-Century-Crofts, 1969.

Rescoria, R. A., \& Wagner, A R. A therity of Pavlovian conditoning. Varidtions in the ettectiveness of reintorcement and nonremtorcement. In A. H Black $\$$ W. F Prokasy (Ed.). Classucal conditioning II Current researih and theory. New York. Appleton-Century-Crotts, 1972.

Rrvusky, $S$. $H$. The role of interterence in associations over a delay $\ln$ W. K. Honig \& H. James (Eds.), Animal memory. New York: Acartemic Fress, 1971

Wagner, A. R., Logan, F, A., Haberlaniti, K., \& Price, 1 Stimulus selection in animal discrimination learning. Journal of Experamental Psychology. 1468, 76, 171180

\section{NOTE}

1. All two-group comparisons ut!lized the Mann-Whitney $T$ and $T$ 'statistıc All sıgnificance values reported are two-talled.

(Received for publication August 26, 1975; revision accepted November 13, 1975.) 